\title{
Ignition Process in a Non-Homogeneous Mixture
}

\author{
Hiroshi Kawanabe \\ Graduate School of Energy Science, \\ Kyoto University, \\ Japan
}

\section{Introduction}

An auto-ignition process of a non-homogeneous mixture is investigated using a numerical calculation based on chemical kinetics and the stochastic approach. This type of autoignition phenomenon is considered as a fundamental process of the initial stage of diesel combustion (Ishiyama, et al., 2003) or homogeneous charged compression ignition (Shimasaki, et al., 2003). In order to investigate these combustion processes, many numerical calculations have been performed and for many of those it has been assumed that the ignition process is dominated by the turbulent mixing (Kong and Reitz, 2000).

However, the fuel-air mixing and chemical reaction progress happen simultaneously for these types of combustion processes. Due to the long ignition delay time and high homogeneity of the mixture, combustion characteristics, such as ignition delay and combustion duration, could be affected equally by non-homogeneity of the mixture, turbulent mixing rate and chemical reaction rate. Therefore, the understanding of those combustion mechanisms is incomplete due to the complexity of the phenomena in which the mixing and chemical processes interact with each other. The main purpose of this chapter is to estimate these effects quantitatively using a numerical method.

Here, n-heptane is assumed as a fuel and its reaction process is calculated by means of a reduced mechanism (Seiser et al., 2000). The non-uniform states of turbulent mixing are statistically described using probability density functions and the stochastic method, which was newly developed from Curl's model (Curl, 1963). Focusing on the effects of mixture heterogeneity on combustion characteristics, such as ignition delay and combustion intensity (rate of temperature rise), the evolution of chemical reactions was calculated for the mixture in which variance in fuel-mass fraction decreases at given rates from the initial value under a fixed mean fuel-mass fraction and a constant pressure. The results show that the start timing of the low-temperature oxidation and ignition delay period are hardly affected by the equivalence-ratio variation, however, combustion duration increases with increasing variance. Furthermore, the combustion duration is mainly affected by the non-homogeneity at the ignition and is not much affected by the mixing rate. 


\section{Numerical models}

\subsection{Mixing model}

In order to describe the homogenization process of a fuel-air mixture by turbulent mixing, the statistical state of the mixture is expressed by means of probability density function (PDF) and the dissipation process is described by a particle-interaction model. In the particle-interaction model, the statistical state $f$ of scalar $\phi$ at time $t$ is represented by the $N$ delta functions $\delta$;

$$
f(\phi ; t)=\frac{1}{N} \sum_{n=1}^{N} \delta(\phi-\phi(n))
$$

Here, $\phi^{*}(n)$ indicates $\phi$ value on the nth particle. In the coalescence/dispersion model proposed by Curl (1963), the state of $f$ at $t+\Delta t$ is calculated from the collision frequency $\omega$. The compositions of a pair of particles, which are selected at random (denoted by $n_{1}$ and $n_{2}$ ), change as;

$$
\left.\phi^{*}\left(n_{1}\right)\right|_{t=t+\Delta t}=\left.\phi^{*}\left(n_{2}\right)\right|_{t=t+\Delta t}=\frac{1}{2}\left(\left.\phi^{*}\left(n_{1}\right)\right|_{t=t}+\left.\phi^{*}\left(n_{2}\right)\right|_{t=t}\right)
$$

Then, within the time interval $\Delta t$, this operation is repeated $\Delta t N \omega$ times.

The change in the value of $\phi^{*}$ is sometimes large, especially in the early stages of mixing, because it is calculated as the average of significantly different quantities of two particles. This tends to cause unrealistic change in the progress of chemical reactions. The modified Curl's model (Janicka, Kolbe and Kollmann, 1979) is one possible method to mitigate this tendency. In this method, the scalar exchange of a pair of particles $\left(n_{1}\right.$ and $\left.n_{2}\right)$ is calculated from a uniform random number $C$ between 0 and 1 ;

$$
\begin{aligned}
& \left.\phi^{*}\left(n_{1}\right)\right|_{t=t+\Delta t}=\left.\phi^{*}\left(n_{1}\right)\right|_{t}+\frac{1}{2} C\left(\left.\phi^{*}\left(n_{2}\right)\right|_{t=t}-\left.\phi^{*}\left(n_{1}\right)\right|_{t=t}\right) \\
& \left.\phi^{*}\left(n_{2}\right)\right|_{t=t+\Delta t}=\left.\phi^{*}\left(n_{2}\right)\right|_{t}-\frac{1}{2} C\left(\left.\phi^{*}\left(n_{2}\right)\right|_{t=t}-\left.\phi^{*}\left(n_{1}\right)\right|_{t=t}\right)
\end{aligned}
$$

This operation is repeated $3 / 2 \Delta t N \omega$ times and can describe statistically the same process as Curl's model. However, the value of $\phi^{*}{ }_{t+\Delta t}$ still changes significantly if $C$ is near 1 . Here, in order to avoid a significant difference between $\phi_{t}^{*}$ and $\phi_{t+\Delta t}^{*} C$ is fixed to a value sufficiently smaller than unity and the replacement procedures are repeated $\Delta t N \omega /(2 C)$ times. In order to confirm the consistency between the present model and Curl's model, a mixing process was calculated starting from the initial state in which fuel and air are perfectly separated.

Time change of variance $v_{m}$ for fuel-mass fraction $\mathrm{mf}$ distribution is shown in Fig. 1. Here, $v_{m}$ is normalized with respect to initial variance $v_{m i}$ and dimensionless time $t^{*}=\omega t$ is used. $C=$ 0.05 and $N=1000$ are adopted. As shown, the time changes of $v_{m} / v_{m i}$ calculated by these three methods are completely equivalent. Meanwhile, Figure 2 shows the time change in $m_{f-}$ PDF. The distributions at smaller $t$ calculated by the present model are similar to Gaussian rather than to the PDFs by the Curl's and modified Curl's models. 


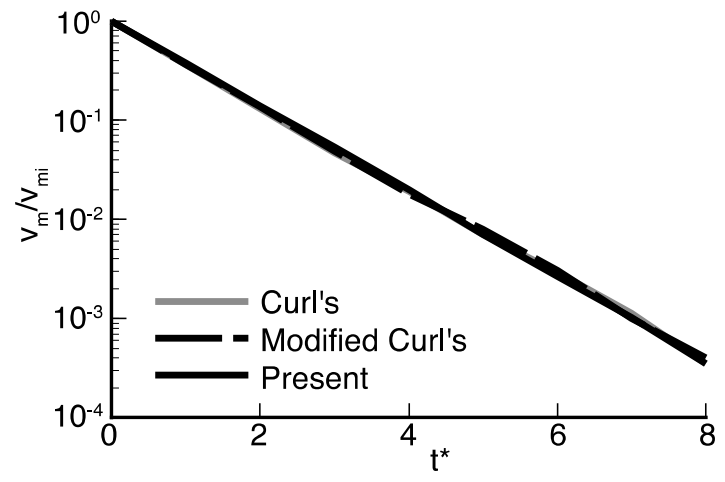

Fig. 1. Course of normalized variance $v_{m} / v_{m i}$ against non-dimensional time $t^{*}$

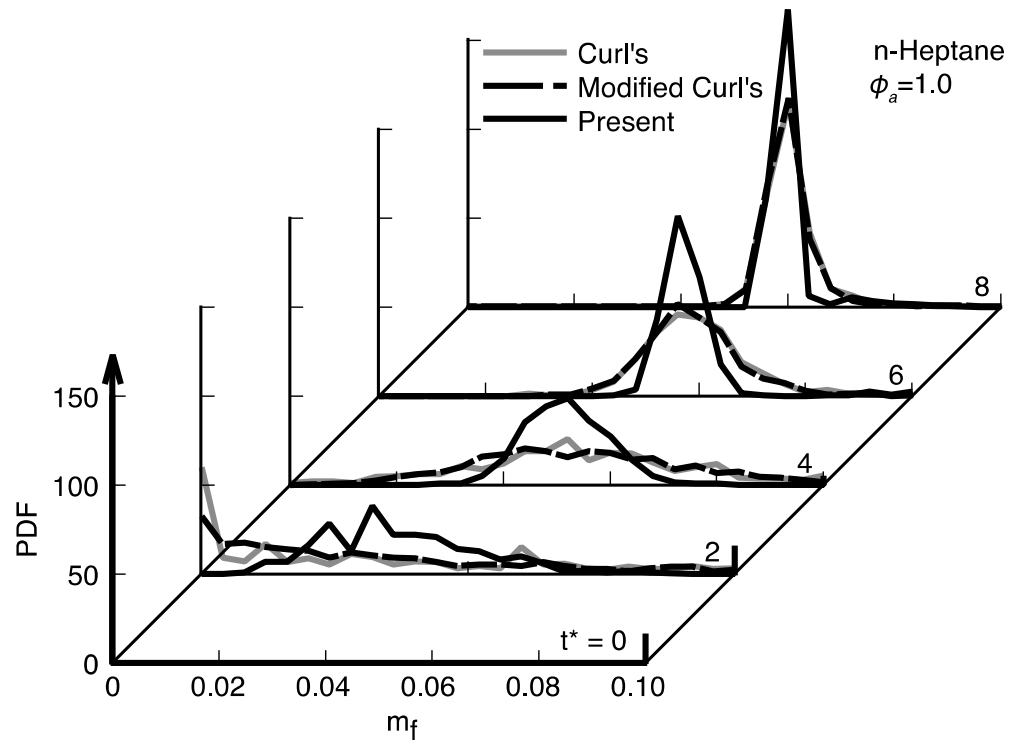

Fig. 2. Temporal change in PDF of fuel-mass fraction $m_{f}$

\subsection{Chemical reaction model}

Here, n-heptane is assumed as a fuel and a chemical reaction system is described by a semidetailed kinetic mechanism (Seiser et al., 2008[Web]). This system consists of 160 chemical species and 1540 elemental reactions, and is selected for reducing computation time.

\section{Results and discussion}

By means of the above-mentioned procedure, an ignition process of non-homogeneous mixture with a constant mixing rate is calculated. For simplicity, the calculation is performed under a constant pressure. The initial temperature $T_{i}$ and pressure $p$ are set to 
$T_{i}=900 \mathrm{~K}$ and $p=4 \mathrm{MPa}$. The initial distribution of fuel-mass fraction is Gaussian with a mean value $m_{f a}$ and a variance $v_{m i}$. Figure 3 shows time histories of mean temperature $T_{a}$ and variance $v_{m}$ for the initial condition of $m_{f}=6.22 \times 10^{-2}$ and $v_{m i}=4.34 \times 10^{-5}$, corresponding to a mean equivalence ratio $\phi_{\mathrm{a}}$ of unity and the standard deviation of $\phi$ of approximately 0.1 . The collision frequency $\omega$ is varied within the range of $0 \mathrm{~s}^{-1}$ to $10000 \mathrm{~s}^{-1}$. For comparison, the result for the case of the homogeneous mixture is also shown. Collision frequency $\omega$ is usually given by $\omega=C_{m} \varepsilon / k$ for the PDF model combined with CFD using the $k-\varepsilon$ turbulence model.

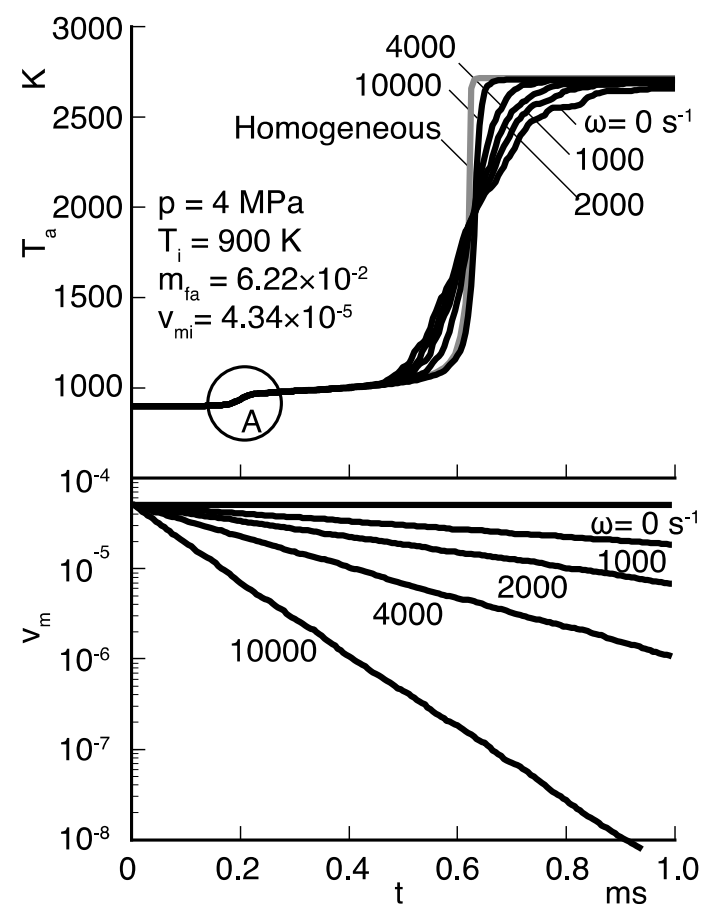

Fig. 3. Courses of mean-temperature $T_{a}$ and $v_{m}$ for the non-homogeneous mixture $\left(\phi_{a}=1.0\right)$

Here, $k$ and $\varepsilon$ represent turbulence energy and its dissipation rate, respectively. $C_{m}$ is fixed at 2, therefore, $\omega=2000 \mathrm{~s}^{-1}$ corresponds approximately to turbulence intensity of $5 \mathrm{~m} / \mathrm{s}$ and scale of $3 \mathrm{~mm}$. For these calculations, the number of fluid particles is fixed to $N=100$. Generally, as collision frequency increases, the start of heat release by hot flame delays and maximum heat release rate increases simultaneously to approach the result of a homogeneous mixture. Meanwhile, the time when the temperature reaches $50 \%$ of adiabatic flame temperature is approximately constant regardless of the collision frequency $\omega$. The reason will be discussed later in Fig. 8. Furthermore, Fig. 4 shows a magnified view of Fig. 3 around the starting points of heat release by cool flame (marked as ' $\mathrm{A}^{\prime}$ ). The change in mean temperature $T_{a}$ is exactly the same, in spite of the change of $\omega$.

Next, in order to clarify the effect of mean equivalence ratio, calculations are performed for lean and rich cases. Fig. 5 shows $T_{a}$ and $v_{m}$ under the conditions of (a) $m_{f a}=3.87 \times 10^{-2}\left(\phi_{a}=\right.$ $0.6)$ and $(b) m_{f a}=1.17 \times 10^{-1}\left(\phi_{a}=2.0\right)$ for the same $\omega$ as in Fig. 3. Here, initial value of variance 


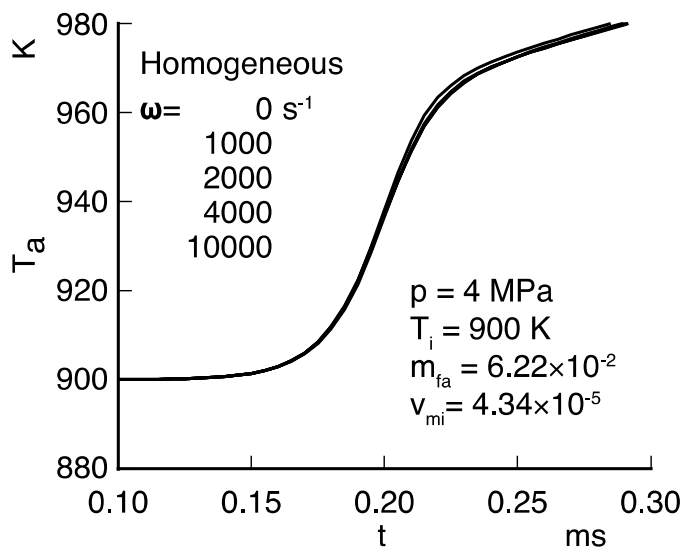

Fig. 4. Temporal changes of Ta due to low temperature oxidation

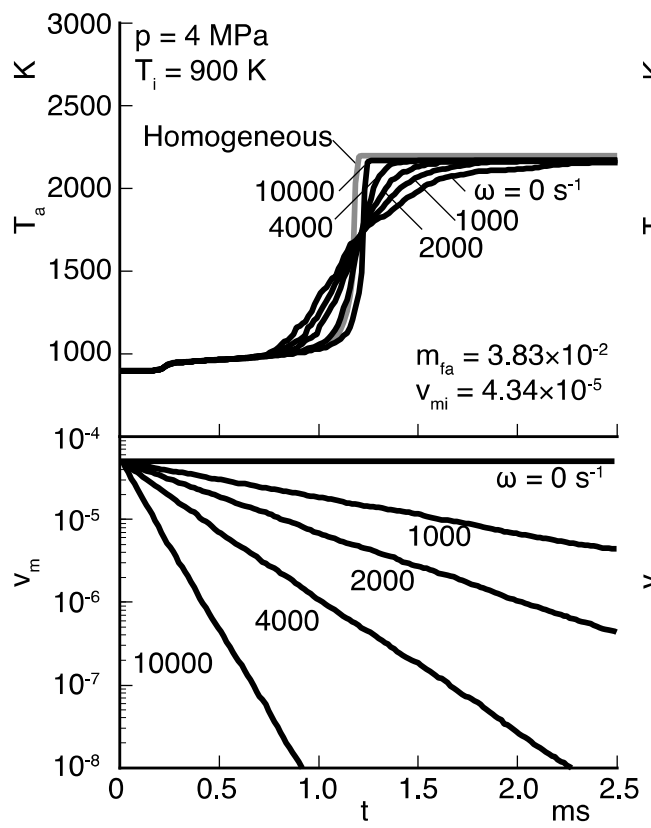

(a) $m_{f a}=3.83 \times 10^{-2}\left(\phi_{a}=0.6\right)$

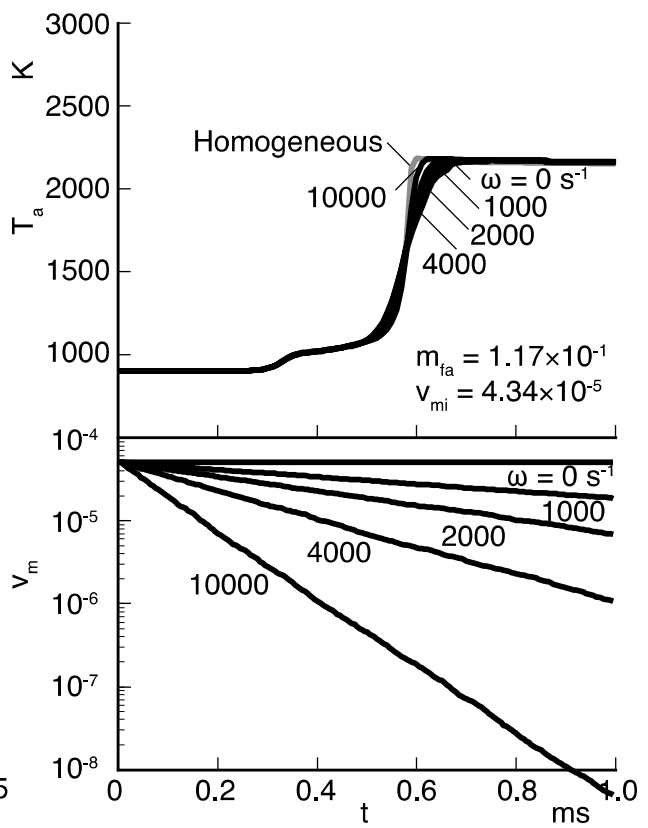

(b) $m_{f a}=1.17 \times 10^{-1}\left(\phi_{a}=2.0\right)$

Fig. 5. Effect of mean mass-fraction $m_{f a}$

is fixed to $v_{m i}=4.34 \times 10^{-5}$. For the two conditions, histories of the mean temperature $T_{a}$ are similar to the result of $\phi_{a}=1.0$ in Fig. 3. For the lean case (a), due to the longer delay of hot flame heat release, the mixture is thought to be more homogeneous and to provide rapid temperature rise. However, the temperature-rising rate at ignition is lower compared to the result of $\phi_{a}=1$. Meanwhile, for the rich case (b), the variance $v_{m}$ at the ignition is comparably large, whereas the temperature rise at the ignition is steep, similar to the homogeneous case. 
In order to clarify the reason why the temperature-rising rate of the non-homogeneous mixture becomes smaller than in the homogenous case, the temporal change of temperature $\mathrm{T}$ and mass fraction of fuel $\mathrm{mf}$ in each fluid particle are examined. Fig. 6 shows the data of

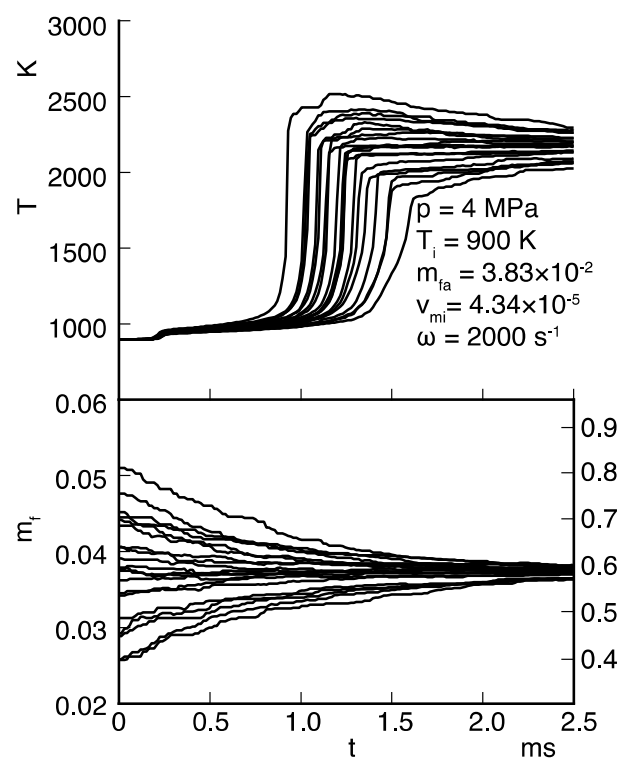

(a) $m_{f a}=3.83 \times 10^{-2}\left(\phi_{a}=0.6\right)$

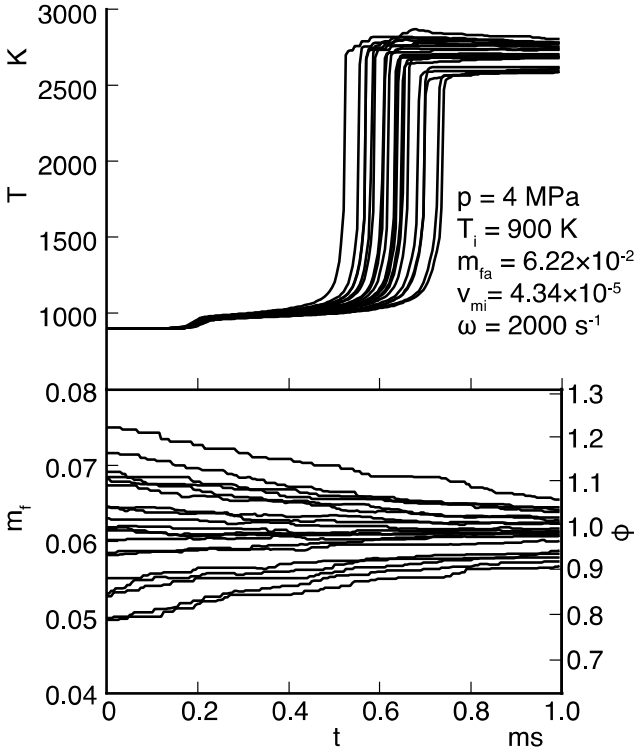

(b) $m_{f a}=6.22 \times 10^{-1}\left(\phi_{a}=1.0\right)$

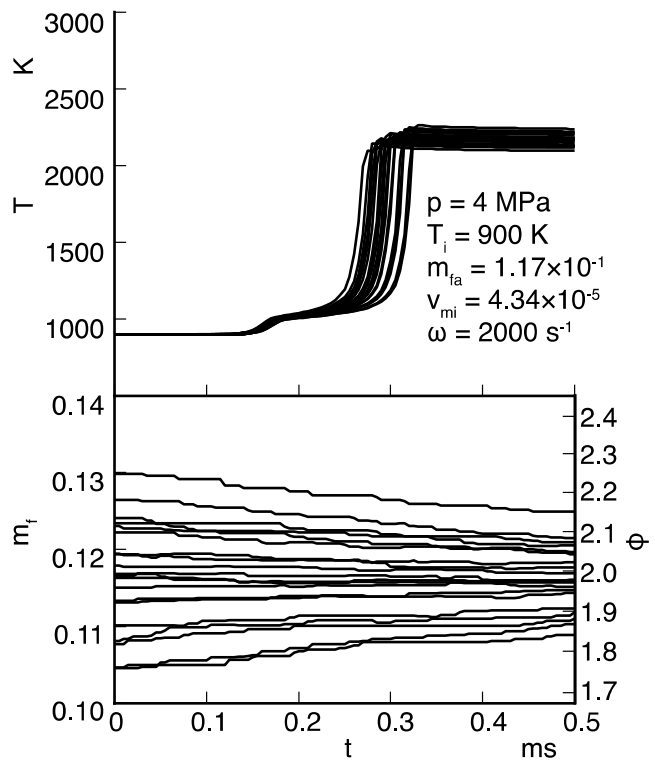

(c) $m_{f a}=1.17 \times 10^{-1}\left(\phi_{a}=2.0\right)$

Fig. 6. Time history of $T$ and $m_{f}$ for each stochastic particle 
20 fluid particles, which are selected randomly, for (a) $m_{f a}=3.83 \times 10^{-2}\left(\phi_{a}=0.6\right)$, (b) $m_{f a}=$ $6.22 \times 10^{-2}\left(\phi_{a}=1.0\right)$ and (c) $m_{f a}=1.17 \times 10^{-1}\left(\phi_{a}=2.0\right)$ at $p=4 \mathrm{MPa}, T=900 \mathrm{~K}$ and $\omega=2000 \mathrm{~s}^{-1}$. In each fluid particle, hot flame occurs with rapid temperature rise when $\mathrm{mf}$ approaches $m_{f a}$. For every case of mean fuel-mass fraction, the hot flame ignition delay varies over a wide range, because the mixture contains a variety of fuel-mass fractions. However, the particleto-particle variation of the hot flame start time is not determined by the variation in fuelmass fraction.

In order to examine the relation between non-homogeneity and temperature rise rate quantitatively, some characteristic times of temperature rise process are defined as shown in Fig. 7. Firstly, the time at 50\% temperature rising between the initial and adiabatic temperatures is expressed as $\tau_{50}$ and that at $95 \%$ as $\tau_{95}$. Next, using these values, temperature rise period $\tau_{i}$ and ignition delay time $\tau_{s}$ are defined as below;

$$
\begin{gathered}
\tau_{i}=2 \times\left(\tau_{50}-\tau_{95}\right) \\
\tau_{s}=\tau_{95}-\tau_{i}
\end{gathered}
$$

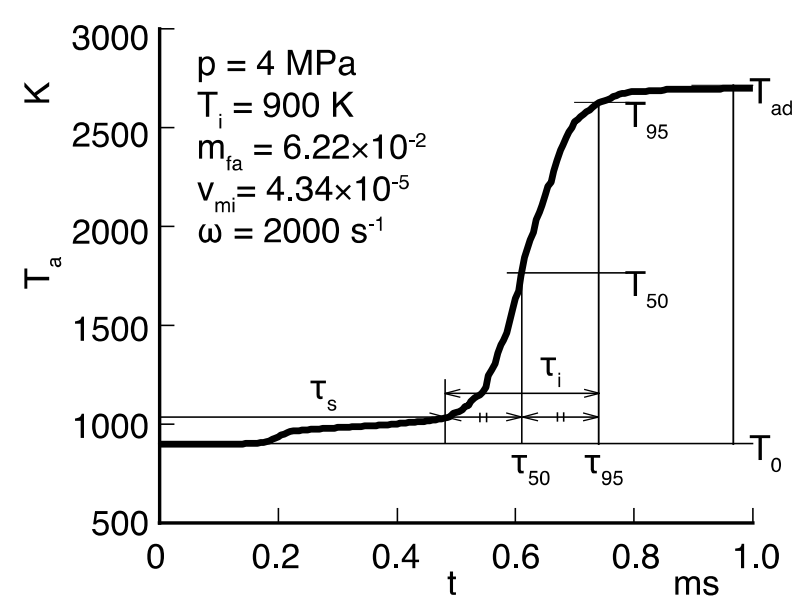

Fig. 7. Definition of ignition delay time $\tau_{s}$ and combustion duration $\tau_{i}$

Based on these values, the ignition processes of non-homogeneous and homogeneous mixture are discussed. $\tau_{s}, \tau_{95}$ and $\tau_{i}$ (marked by an arrow) are displayed for nonhomogeneous mixtures with average equivalence ratios $\phi_{a}$ of 0.6, 1.0, and 2.0. In Fig. 8, PDF for $\mathrm{mf}$ at $t=\tau_{50}$ is also displayed for each mixture. In addition, the curves of $\tau_{s}$ and $\tau_{95}$ calculated for homogeneous mixtures are drawn. Within this $m_{f}$-condition, ignition delay $\tau_{s}$ of the homogeneous mixture becomes shorter with increasing $m_{f}$. At the same time, $\tau_{i}$ becomes larger for the leaner and richer sides. Here, ignition delay time of each fluid particle varies due to the variation of equivalence ratio at ignition, therefore, the temperature rise period increases. In addition, $m_{f}$ dispersion becomes larger for the richer condition, due to shorter ignition delay time. The change in ignition delay against $\mathrm{mf}$ 
around $\phi_{a}=2.0$ is small so that $\tau_{i}$ also becomes smaller in spite of the wide distribution of $m_{f}$. On the other hand, for the leaner side around $\phi_{a}=0.6$, the distribution width is narrow, whereas $\tau_{s}$-change against $\mathrm{mf}$ becomes larger than in the stoichiometric case. Then $\tau_{i}$ becomes longer.

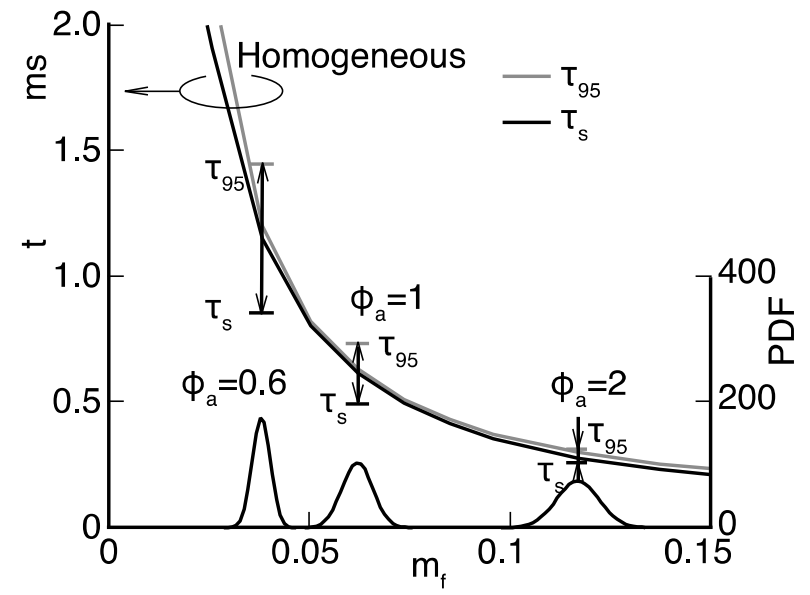

Fig. 8. Changes of ignition delay time $\tau_{\mathrm{s}}$ and combustion duration $\tau_{i}$

In order to confirm the effect of mixing rate on the combustion process, temperature histories are compared for different mixing rates at the same $m_{f}$-variance in the middle of hot flame temperature rise, as shown in Fig. 9. The calculation starts with $\omega=2000 \mathrm{~s}^{-1}$, then $\omega$ is suddenly increased to $10000 \mathrm{~s}^{-1}$ just before the ignition. The obtained temperature history differs from that of $\omega=10000 \mathrm{~s}^{-1}$ and is similar to that of $\omega=4000 \mathrm{~s}^{-1}$, whose variance of $m_{f}$-PDF at $\tau_{50}$ is nearly equal to this $\omega$ jumping-up case. This result shows that the rate of temperature rise is strongly affected by the $m_{f}$-distribution at ignition rather than the mixing rate. Fig. 10 shows the correlation plots of (a) $\tau_{i}-\omega$ and (b) $\tau_{i}-v_{m 50}$. Here, $v_{m 50}$ represents the variance of $m_{f}$-PDF at $\tau_{50}$. In this case these plots are calculated for wide ranges of $v_{m i}, T_{i}$ and $\omega$ with fixed $p=4.0 \mathrm{MPa}$ and $m_{f a}=6.22 \times 10^{-2}\left(\phi_{a}=\right.$ 1.0). For the plots on (a), $\tau_{i}$ scatters widely even at the same $\omega$, however, for (b), the plots distribute on a certain curve. This indicates the great influence of $m_{f}$ variance on combustion duration.

A similar calculation is performed for the case of longer ignition delay and lower temperature rise rate, which is set by $m_{f a}=1.95 \times 10^{-2}\left(\phi_{a}=0.3\right), p=2.0 \mathrm{MPa}$ and $T_{i}=900 \mathrm{~K}$.

In this case, the mixture is comparably lean and ambient pressure is low so that $\tau_{s}$ and $\tau_{i}$ become much longer than in the case shown in Fig. 3. Fig. 11 shows the results for $\omega=0 \mathrm{~s}^{-1}$, $200 \mathrm{~s}^{-1}, 400 \mathrm{~s}^{-1}, 1000 \mathrm{~s}^{-1}$ and $2000 \mathrm{~s}^{-1}$. Here, the ignition delay time is longer, therefore, mixture at ignition becomes more homogeneous for the case of $\omega>2000 \mathrm{~s}^{-1}$. The ignition delay time $\tau_{s}$ and temperature rise rate become larger with increasing mixing rate, which is similar to the results shown in Fig. 3. Also, $\tau_{50}$ is almost constant against $\omega$. 


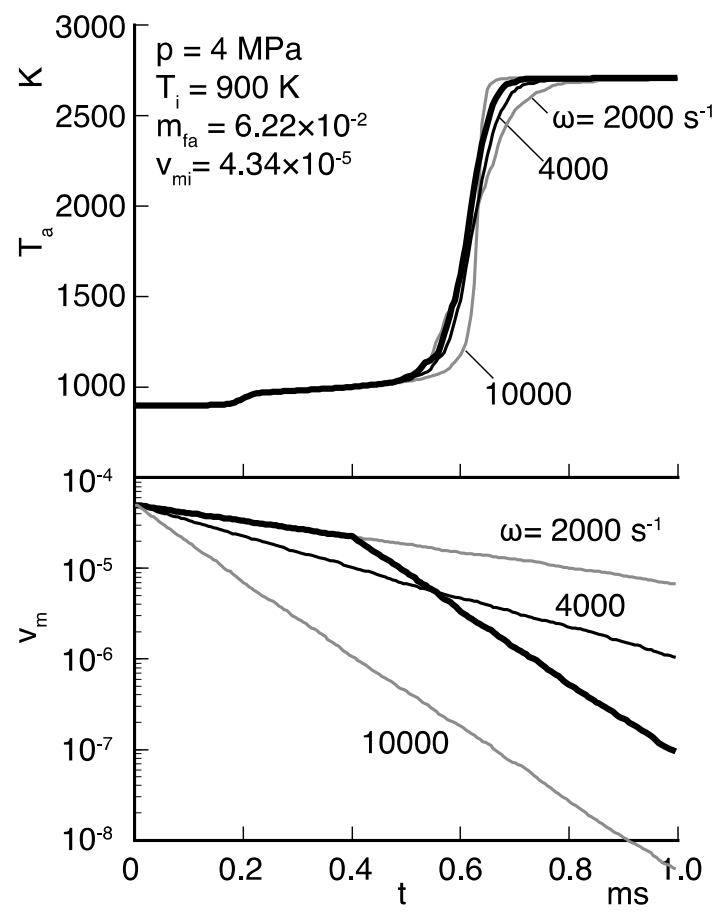

Fig. 9. Effect of collision frequency $\omega$ on combustion duration

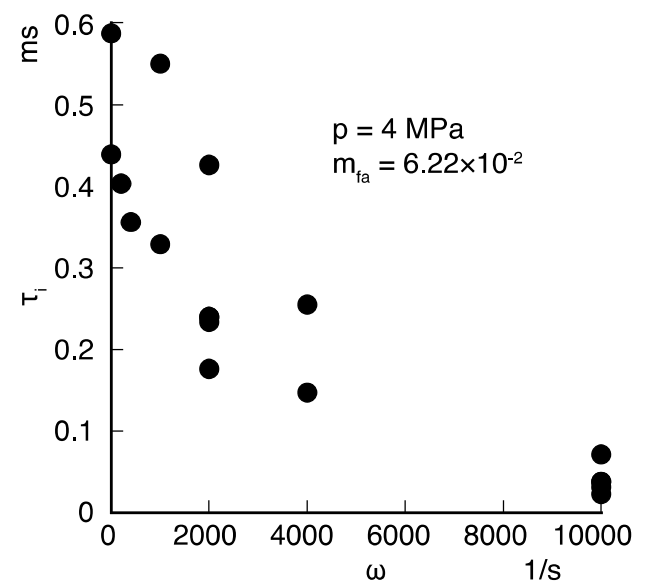

(a) $\tau_{i}-\omega$ Correlation

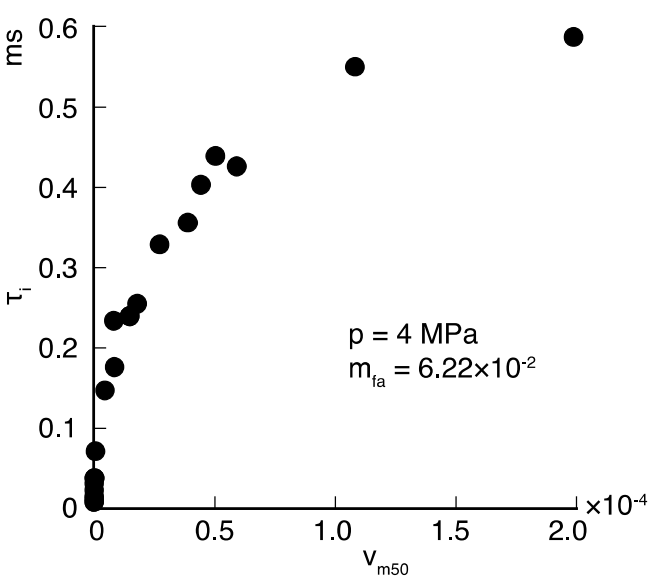

(b) $\tau_{i}-v_{m 50}$ Correlation

Fig. 10. Correlations between combustion duration $\tau_{i}$ - collision rate $\omega$ and $\tau_{i}$ - mass variation at $t=\tau_{50}$ 


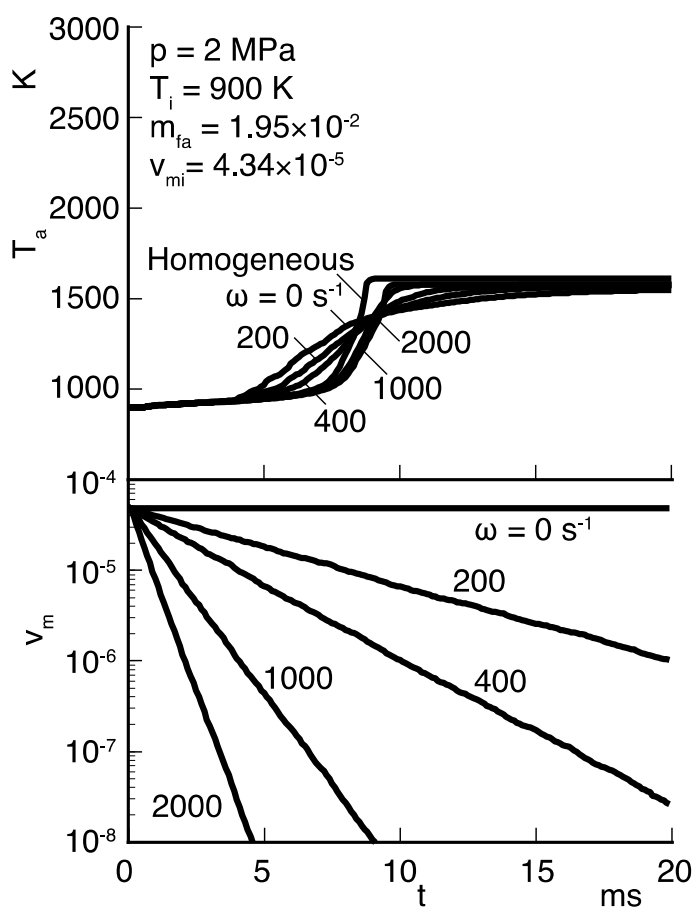

Fig. 11. Courses of mean-temperature $T_{a}$ and $v_{m}$ for PCCI-like condition

\section{Conclusion}

An auto-ignition process of a non-homogeneous mixture in fuel concentration was fundamentally investigated by means of a numerical calculation based on chemical kinetics and the stochastic approach. The auto-ignition process of n-heptane is calculated by means of a semi-detailed mechanism and the non-uniform state of turbulent mixing is statistically described by means of probability density functions and the stochastic method. The following conclusions are derived from the results:

1. For the auto-ignition process of a non-homogeneous mixture during the mixing process, ignition delay time of the cool flame is almost constant against the mixing rate. On the other hand, ignition delay time of hot flame becomes longer with increasing mixing rate. This is because the hot flame ignition delay is more sensible to equivalence ratio than the cool flame delay.

2. For the temperature rising process of hot flame, start points of heat release vary depending on equivalence ratio in a non-homogeneous mixture. Therefore, the rise period increases with increasing non-homogeneity. Also, the temperature rise rate due to heat release of hot flame increases with increasing mixing rate.

3. The tendencies described above are the same for the case of changing equivalence ratio, initial temperature and pressure. 
4. Ignition delay time of each fluid particle varies due to the variation of equivalence ratio at ignition, therefore, the temperature rise period increases. In addition, the temperature rise rate becomes larger with decreasing variance of fuel-mass fraction distribution.

\section{Nomenclature}

C: $\quad$ Coefficient of modified Curl's model

$C_{m}$ : Coefficient of turbulent mixing

$f: \quad$ Statistical state function

$m_{f}: \quad$ Fuel-mass fraction

$m_{f a}: \quad$ Mean value of $m_{f}$

N: $\quad$ Total number of fluid particles

$t$ : Time

$t^{*}$ : Dimensionless time

$p: \quad$ Pressure

T: $\quad$ Temperature

$T_{a}: \quad$ Mean temperature

$T_{i}: \quad$ Initial temperature

$v_{m}: \quad$ Variance of $m_{f}$

$v_{m 50}: \quad$ vm at $\tau_{50}$

$v_{m i}: \quad$ Initial value of $v_{m}$

$\delta$ : Delta function

$\phi$ : Scalar

$\phi_{a}: \quad$ Mean equivalence ratio

$\tau_{50}$ : Time at $50 \%$ temperature rise

$\tau_{95}: \quad$ Time at $95 \%$ temperature rise

$\tau_{i}: \quad$ Combustion duration

$\tau_{s}: \quad$ Ignition delay of hot flame

$\omega$. Collision frequency

\section{References}

Shimazaki, N., Tsurushima, T. and Nishimura, T., Dual-Mode Combustion Concept with Premixed Diesel combustion by Direct Injection near Top Dead Center, SAE Paper, 2003-01-0742.

Ishiyama, T., Shioji, M. and Ihara, T., Analysis of Ignition Processes in a Fuel Spray Using an Ignition Model Including Turbulent Mixing and Reduced Chemical Kinetics, Int. J. of Engine Research, Vol. 4, No. 3 (2003), 155-162.

Kong, S-C., Reitz, R. D., Modeling HCCI Engine Combustion Using Detailed Chemical Kinetics with Combustion of Turbulent Mixing Effects, ASME Paper 2000-ICE-306, 2000.

Curl, R. L., Dispersed Phase Mixing: I. Theory and Effects in Simple Reactors, A. I. Ch. En. J., Vol. 9, No. 2 (1963), 175-181. 
Janicka, J., Kolbe W, and Kollmann, W., Closure of the Transport Equation for the Probability Density Function of Turbulent Scalar Fields, J. of Non-equilibrium Thermodynamics, Vol. 4 (1979), 47.

Seiser, H., et al., Extinction and Autoignition of n-Heptane in Counterflow Configuration, Proc. of the Combustion Institute 28 (2000), pp. 2029-2037. 


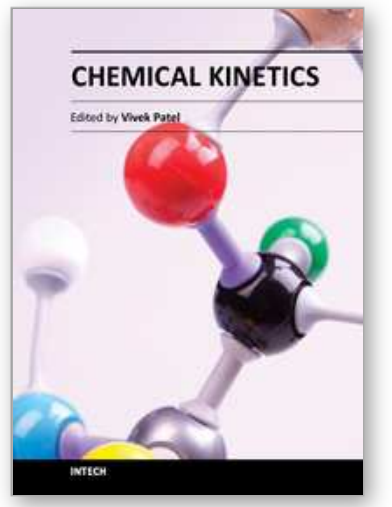

\author{
Chemical Kinetics \\ Edited by Dr Vivek Patel
}

ISBN 978-953-51-0132-1

Hard cover, 344 pages

Publisher InTech

Published online 29, February, 2012

Published in print edition February, 2012

Chemical Kinetics relates to the rates of chemical reactions and factors such as concentration and temperature, which affects the rates of chemical reactions. Such studies are important in providing essential evidence as to the mechanisms of chemical processes. The book is designed to help the reader, particularly students and researchers of physical science, understand the chemical kinetics mechanics and chemical reactions. The selection of topics addressed and the examples, tables and graphs used to illustrate them are governed, to a large extent, by the fact that this book is aimed primarily at physical science (mainly chemistry) technologists. Undoubtedly, this book contains "must read" materials for students, engineers, and researchers working in the chemistry and chemical kinetics area. This book provides valuable insight into the mechanisms and chemical reactions. It is written in concise, self-explanatory and informative manner by a world class scientists in the field.

\title{
How to reference
}

In order to correctly reference this scholarly work, feel free to copy and paste the following:

Hiroshi Kawanabe (2012). Ignition Process in a Non-Homogeneous Mixture, Chemical Kinetics, Dr Vivek Patel (Ed.), ISBN: 978-953-51-0132-1, InTech, Available from: http://www.intechopen.com/books/chemicalkinetics/ignition-process-in-non-homogeneous-mixture

\section{INTECH}

open science | open minds

\author{
InTech Europe \\ University Campus STeP Ri \\ Slavka Krautzeka 83/A \\ 51000 Rijeka, Croatia \\ Phone: +385 (51) 770447 \\ Fax: +385 (51) 686166 \\ www.intechopen.com
}

\author{
InTech China \\ Unit 405, Office Block, Hotel Equatorial Shanghai \\ No.65, Yan An Road (West), Shanghai, 200040, China \\ 中国上海市延安西路65号上海国际贵都大饭店办公楼 405 单元 \\ Phone: +86-21-62489820 \\ Fax: +86-21-62489821
}


(C) 2012 The Author(s). Licensee IntechOpen. This is an open access article distributed under the terms of the Creative Commons Attribution 3.0 License, which permits unrestricted use, distribution, and reproduction in any medium, provided the original work is properly cited. 